\title{
Editorial
}

\section{Shock and Vibration Induced by Mining Extraction 2016}

\author{
Caiping Lu, ${ }^{1}$ Linming Dou, ${ }^{2}$ Nong Zhang, ${ }^{1}$ Marcin A. Lutyński, ${ }^{3}$ and Shimin Liu ${ }^{4}$ \\ ${ }^{1}$ School of Mines, China University of Mining and Technology, Xuzhou 221116, China \\ ${ }^{2}$ State Key Laboratory of Coal Resources and Safe Mining, China University of Mining and Technology, Xuzhou 221116, China \\ ${ }^{3}$ Institute of Mining Engineering, Faculty of Mining and Geology, Silesian University of Technology, Ul. Akademicka 2, Gliwice, Poland \\ ${ }^{4}$ Department of Energy and Mineral Engineering, School of Earth and Mineral Sciences, The Pennsylvania State University, \\ State College, PA 16802, USA \\ Correspondence should be addressed to Caiping Lu; cplucumt@126.com
}

Received 22 September 2016; Accepted 22 September 2016

Copyright (C) 2016 Caiping Lu et al. This is an open access article distributed under the Creative Commons Attribution License, which permits unrestricted use, distribution, and reproduction in any medium, provided the original work is properly cited.

With the increasing depth and intensity of coal mining, the rockburst and correspondingly induced dynamic disasters are aggravating, which has been a serious threat to the safety of coal mines. According to reliable statistics, only 32 coal mines were characterized by rockburst danger until 1985 in China; unfortunately, by the end of 2014, nearly 147 coal mines were classified as rockburst tendency. Simultaneously, the mining depth of about 50 coal mines reaches or surpasses $1000 \mathrm{~m}$. In the period of 2004-2014, more than 35 fatal rockbursts occurred, which cruelly killed over 300 workers and caused thousands of injures. In despite of lack of accurate data about rockburst in coal mines in other countries, we believe that the rockburst should be a ubiquitous dynamic phenomenon in deep coal mines in the world.

It has been verified that the mining-induced shock or vibration can easily trigger strong tremor and even cause rockburst disaster in high-stress concentration region by experimental and field investigations. Therefore, it is very urgent to essentially understand the mining-induced shock and vibration waves in coal mines.

Our special issue is dedicated to fundamental understanding of mining-induced shock and vibration waves mainly concentrated on mechanical principles, propagation and attenuation laws, monitoring and warning methods, and prevention of catastrophic shock. A total of 6 papers have been accepted for publication in the special issue, which is mainly divided into four aspects that are the deformation and failure mechanism of coal and rock with rockburst tendency, the propagation and attenuation rules of shock wave including blasting waves, early warning based on acoustic emission (AE), and innovative supporting technologies of roadway in deep coal mines, respectively. By rigorous review and negotiation, two highlights are presented that are the numerical analysis on failure modes and mechanisms of mine pillars and the reduction effect of stress waves caused by water jet slotting near blasting source.

Rockburst in coal mines is a worldwide conundrum poorly understood, the early-warning indexes are confusing and exasperating; especially, its prevention is yet not effectively resolved. The satisfactory solution compulsorily requires the worldwide efforts and cooperation in coal mining and rock mechanics community.

\author{
Caiping $L u$ \\ Linming Dou \\ Nong Zhang \\ Marcin A. Lutyński \\ Shimin Liu
}




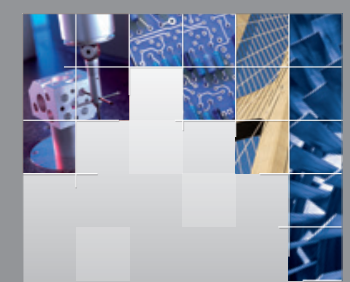

\section{Enfincering}
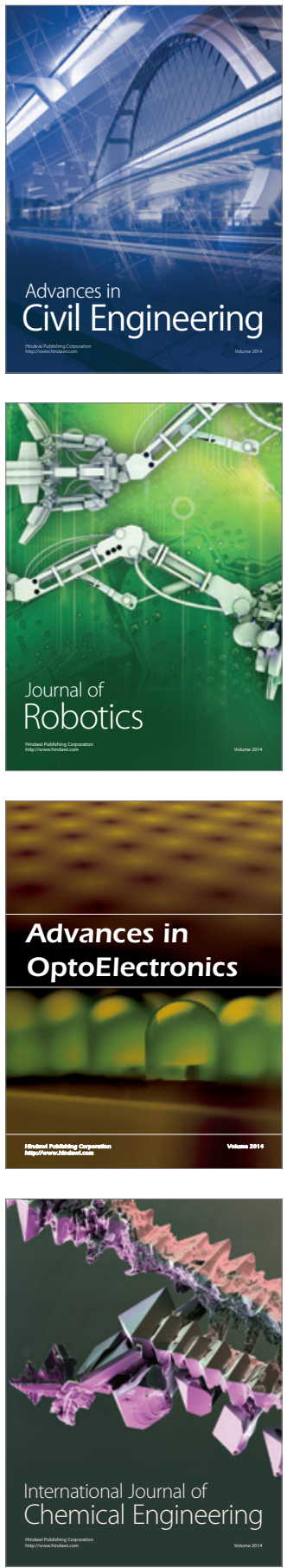

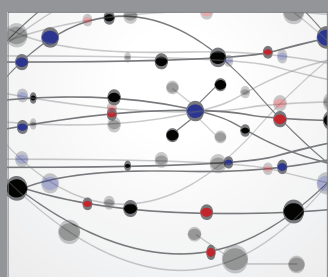

The Scientific World Journal

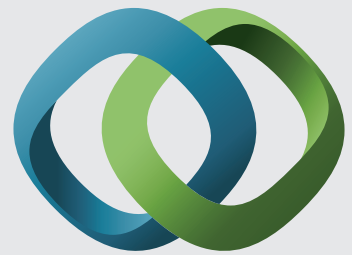

\section{Hindawi}

Submit your manuscripts at

http://www.hindawi.com
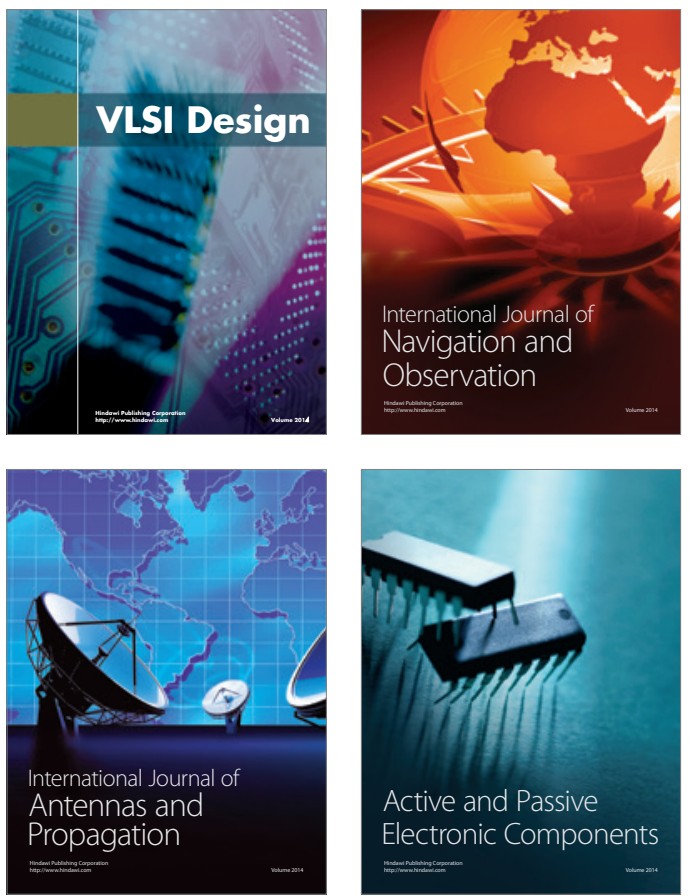
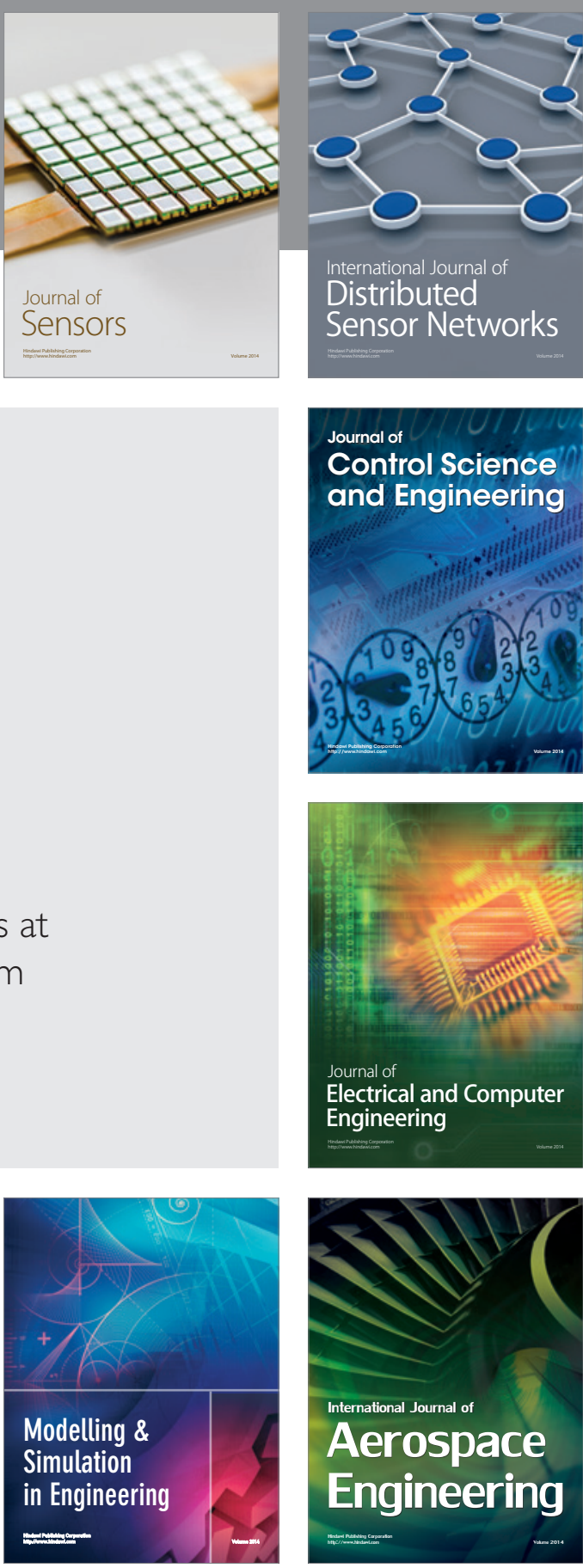

International Journal of

Distributed

Sensor Networks

Journal of

Control Science

and Engineering
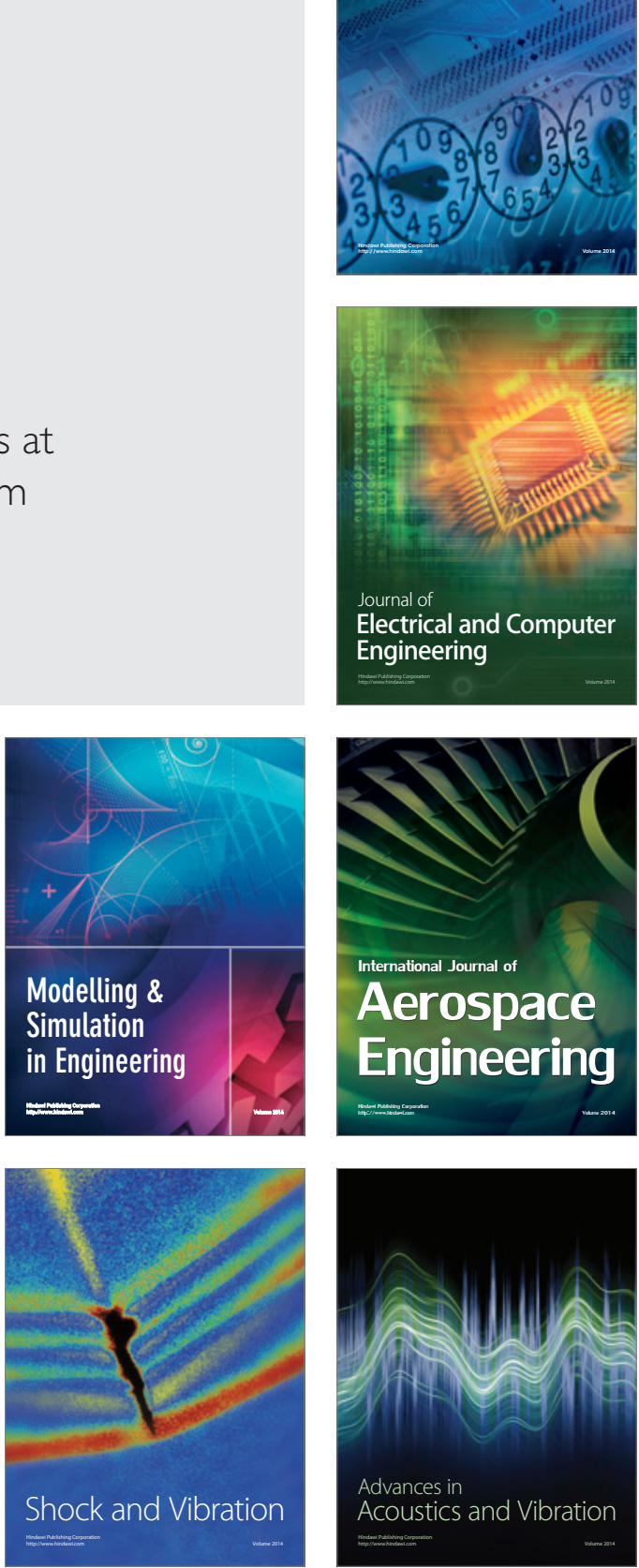